Full-length article

\title{
Modulation of P-glycoprotein function by amlodipine derivatives in brain microvessel endothelial cells of rats ${ }^{1}$
}

\author{
Bian-sheng JI, Ling HE, Guo-qing LIU² \\ Department of Pharmacology, China Pharmaceutical University, Nanjing 210009,China
}

\section{Key words}

amlodipine derivatives; CJX1; CJX2; verapamil P-glycoprotein; blood brain barrier; vascular endothelium

\author{
${ }^{1}$ Project supported by Natural Science Founda- \\ tion of Jiangsu Province (No BK2004110). \\ ${ }^{2}$ Correspondence to Prof Guo-qing LIU. \\ Phn 86-25-8335-2126. \\ E-mail Liugq@vip.163.com \\ Received 2004-06-11 \\ Accepted 2004-11-08
}

doi: $10.1111 / \mathrm{j} .1745-7254.2005 .00028 . x$

\begin{abstract}
Aim: To investigate whether the amlodipine derivatives, CJX1 and CJX2, have a modulative effect on P-glycoprotein (P-gp) function in rat brain microvessel endothelial cells (RBMEC). Methods: Isolated RBMEC were cultured in DMEM/ F12 (1:1) medium. The amount of intracellular rhodamine (Rh123) was determined, using a fluorescence spectrophotometer, to evaluate the function of P-gp. Results: The accumulation of Rh123 in RBMEC was potentiated in a concentrationdependent manner after incubation with CJX1 and CJX2 at 1, 2.5, 5, and 10 $\mu \mathrm{mol} / \mathrm{L}(P<0.01)$, but no accumulation of Rh123 was observed in human umbilical vein endothelial cells after incubation with CJX1 and CJX2 $10 \mu \mathrm{mol} / \mathrm{L}$ $(P>0.05)$. Accumulation of intracellular Rh123 was increased and efflux of intracellular Rh123 was decreased in a time-dependent manner from 0-100 min after $\mathrm{CJX} 1$ and CXJ2 at $10 \mu \mathrm{mol} / \mathrm{L}$ treatment. The inhibitory effect of CJX1 and CJX2 on P-gp function was reversible and remained even at $120 \mathrm{~min}$ after removal of CJX1 and CJX2 at $2.5 \mu \mathrm{mol} / \mathrm{L}$ from the medium. Conclusion: CJX1 and CJX2 exhibited a potent effect in the inhibition of P-gp function in vitro.
\end{abstract}

\section{Introduction}

The treatment of cancer with chemotherapeutic drugs is frequently impaired or ineffective as a result of acquired resistance of tumor cells. This phenomenon is termed as multidrug resistance (MDR) and characterized by the over-expression of P-glycoprotein (P-gp) at the surface of cancer cells. As a $170 \mathrm{kDa}$ protein, P-gp is encoded by MDR gene and belongs to a membrane transporter of the $\mathrm{ABC}$ superfamily. It acts as an energy-dependent drug efflux pump preventing adequate intracellular accumulation of a broad range of cytotoxic drugs including anthracyclines, Vinca alkaloids, epipodophyllotoxins, and taxanes ${ }^{[1-3]}$. P-gp is also expressed in normal tissues such as the endothelial cells of the blood brain barrier (BBB) capillaries ${ }^{[4]}$. The capillary endothelial cells protect the brain against many exogenous toxin injuries and sudden fluctuation in the levels of systemic substances. The hydrophobic agents, such as vinblastine and doxorubicin and lipid-soluble compounds, such as cyclosporin A, cannot accumulate in the brain ${ }^{[5-7]}$. P-gp expression in the $\mathrm{BBB}$ capillaries is responsible for the extru- sion of these compounds from the endothelial cells, and thereby attenuates the accumulation of the drugs in the brain leading to the failure of therapy for the brain disease. There are a variety of agents, such as verapamil (Ver) and cyclosporine $\mathrm{A}$ for overcoming $\mathrm{MDR}^{[8,9]}$. However, vera-pamil and cyclosporine A, are used as anti-arrhythmic agents and immunosuppressants, respectively. Therefore, they will cause side effects when used as MDR-reversing agents. In light of these findings, the development of compounds specially inhibiting P-gp function in cancer cells or BBB may contribute to the treatment of cancers and central nervous system diseases. Amlodipine, a calcium channel antagonist, belongs to dihydropyridines family and is currently applied in the treatment of hypertension ${ }^{[10]}$. A previous report has revealed that amlodipine has an inhibitory effect on P-gpmediated transport of dauxorubicin and digoxin ${ }^{[11]}$. CJX1 and CJX2, the amlodipine derivatives, were synthesized by substituting the hydrogen of the amino group on amlodipine with 4,5-dihydro-imidazole and 4,5-dihydro-thiazole, respectively. The aim of this study was to investigate the 
effects of CJX1 and CJX2 on the P-gp function in rat brain microvessel endothelial cells (RBMEC).<smiles>COC(=O)C1C(CCN)NC(C)=C(C(C)=O)C1c1ccccc1Cl</smiles><smiles>CCOC(=O)C1C(COCCNC2=NCCN2)NC(C)=C(C(C)=O)C1c1ccccc1Cl</smiles><smiles>CCOC(=O)C1C(CNC2=NCCS2)NC(C)=C(C(=O)OCc2ccccc2)C1c1ccccc1Cl</smiles>

Figure 1. The chemical structure of amlodipine, CJX1, and CJX2.

\section{Materials and methods}

Materials The cell line of human umbilical vein endothelial cells (HUVEC) was a gift from Prof Zhuang ZHANG (Beijing University of Chinese Medicine); CJX1 $\left(M_{\mathrm{r}} 471\right)$ and CJX2 $\left(M_{\mathrm{r}} 488\right)$ were obtained from Dr Yun-gen XU (Novel Drug Research Centre, China Pharmaceutical University). Rhodamine123 (Rh123) and verapamil were purchased from Sigma Co (St Louis, USA). Fetal calf serum and DMEM/F12 (1:1) medium were purchased from GIBCO (USA). All other chemicals used in the experiments were commercial products of reagent grade.

Culture of RBMEC RBMEC were isolated according to the method of Abbott et al ${ }^{[12]}$ with minor modification. Isolated cortex from ten rats was placed in ice-cold phosphate-buffered saline (PBS). After removal of surface ves- sels and meninges, cortex gray matter was minced and incubated at $37^{\circ} \mathrm{C}$ for $25 \mathrm{~min}$ in D-Hanks' solution containing $0.05 \%$ trypsin. The samples were filtered through a $150-\mu \mathrm{m}$ nylon mesh. After centrifugation at $800 \times g$ for $5 \mathrm{~min}$, the pellet was re-suspended in PBS containing $20 \%$ bovine serum albumin (BSA) and centrifuged at $2000 \times g$ at $37^{\circ} \mathrm{C}$ for $5 \mathrm{~min}$. After removal of fat, cell debris, and myelin floating on BSA, the pellet containing microvessels was resuspended and incubated in PBS containing $0.1 \%$ collagenase II at $37^{\circ} \mathrm{C}$ for $30 \mathrm{~min}$. The microvessels were finally collected by centrifugation at $800 \times g$ for $5 \mathrm{~min}$, then the pellet was washed twice with PBS and cultured in DMEM/F12 (1:1) medium supplemented with $20 \%$ fetal bovine serum at $37^{\circ} \mathrm{C}$ in a $5 \% \mathrm{CO}_{2}$ humidified atmosphere.

Intracellular Rh123 accumulation assay RBMEC were seeded at a density of $5 \times 10^{7} / \mathrm{L}$ in 24 -well plates. After reaching confluence, cell monolayers were exposed to Rh123 5 $\mu \mathrm{mol} / \mathrm{L}$ in serum-free DMEM/F12 medium containing CJX1 and CJX2 at $1,2.5,5$, and $10 \mu \mathrm{mol} / \mathrm{L}$ at $37^{\circ} \mathrm{C}$ for $90 \mathrm{~min}$, respectively. Verapamil was used as a positive control for an P-gp inhibitor. After incubation, the medium was removed, and all monolayers were washed three times with ice-cold PBS and then dissolved in 1\% Triton X-100. Fluorescence of Rh123 was measured using fluorescence spectrophotometer and concentration of Rh123 was calculated from the fluorescence value on the Rh123 standard curve. The amount of Rh123 in cell samples was normalized with the amount of protein in each sample as described previously $^{[13,14]}$.

Rh123 uptake assay RBMEC were seeded at a density of $5 \times 10^{7} / \mathrm{L}$ in 24 -well plates, and then incubated in DMEM/ F12 (1:1) medium containing Rh123 at $5 \mu \mathrm{mol} / \mathrm{L}$ in the presence or absence of CJX1 or CJX2 $10 \mu \mathrm{mol} / \mathrm{L}$ at $37^{\circ} \mathrm{C}$ in a humidified atmosphere of $5 \% \mathrm{CO}_{2}$ for $10,25,45,60$, and 90 min, respectively. After removal of the medium, the cell monolayers were washed three times in ice-cold PBS and dissolved in $1 \%$ Triton X-100. The amount of Rh123 was determined as described in the accumulation assay. The uptake constant $\left(k_{\mathrm{up}}\right)$ was obtained by fitting the data to $F_{t}=F_{\mathrm{ss}}$ $\left(1-\mathrm{e}^{-k t}\right)$, where $F_{t}$ is the amount of Rh123 at time $t, F_{\mathrm{ss}}$ is the amount of Rh123 at $90 \mathrm{~min}$. The amount of intracellular Rh123 was plotted against time.

Rh123 efflux assay The RBMEC were incubated in the medium containing $\mathrm{Rh} 1235 \mu \mathrm{mol} / \mathrm{L}$ at $37^{\circ} \mathrm{C}$ in a humidified atmosphere of $5 \% \mathrm{CO}_{2}$ for $90 \mathrm{~min}$. After washing three times in ice-cold PBS, RBMEC were incubated in the presence or absence of CJX1 and CJX2 1-10 $\mu \mathrm{mol} / \mathrm{L}$ or verapamil $10 \mu \mathrm{mol} / \mathrm{L}$ at $37^{\circ} \mathrm{C}$ for $5,10,25,30,60$, and $90 \mathrm{~min}$, respectively. The amount of intracellular Rh123 was determined 
as described in the accumulation assay. The efflux constant $\left(k_{\mathrm{e}}\right)$ of CJX1 and CJX2 $10 \mu \mathrm{mol} / \mathrm{L}$ was obtained by fitting the data to $F_{t}=F_{\mathrm{o}} \mathrm{e}^{-k t}$, where $F_{t}$ is the amount of Rh123 at time $t$. The amount of intracellular Rh123 was plotted against time.

Persistence of CJX1 and CJX2 activity The RBMEC were incubated in the medium containing Rh123 $5 \mu \mathrm{mol} / \mathrm{L}$ in the presence or absence of CJX1 and CJX2 $2.5 \mu \mathrm{mol} / \mathrm{L}$ or verapamil $2.5 \mu \mathrm{mol} / \mathrm{L}$ in the humidified atmosphere of $5 \%$ $\mathrm{CO}_{2}$ for $90 \mathrm{~min}$ at $37^{\circ} \mathrm{C}$, respectively. After washing three times in rhodamine-free and drug-free medium, the amount of intracellular Rh123 was measured after 10, 30, 60, 90, and $120 \mathrm{~min}$, respectively. The amount of Rh123 in cell samples at different time points was determined as described in the accumulation assay. $T_{0}$ represents the amount of Rh123 which was monitored immediately after incubation with CJX1, CJX2 or verapamil.

Data analysis All data were expressed as mean \pm SD and analyzed by $t$-test.

\section{Results}

Effect of CJX1 and CJX2 on intracellular accumulation of Rh123 After RBMEC were incubated with Rh123 for $90 \mathrm{~min}$ in the presence of CJX1 and CJX2 1-10 $\mu \mathrm{mol} / \mathrm{L}$, the amount of intracellular Rh123 was greatly increased in a concentration-dependent manner compared with the control group $(P<0.01)$. Accumulation of Rh123 was not increased in HUVEC. The amount of intracellular Rh123 in CJX1 10 $\mu \mathrm{mol} / \mathrm{L}$-treated group was comparable to that of the verapamil $10 \mu \mathrm{mol} / \mathrm{L}$-treated group (Table 1).

Effect of CJX1 and CJX2 on uptake of Rh123 After the RBMEC were incubated in the presence of CJX1 and CJX2 $10 \mu \mathrm{mol} / \mathrm{L}, \mathrm{Rh} 123$ was accumulated in a time-dependent manner from 0-100 min. The rate constants $\left(k_{\text {up }}\right)$ of the uptake in CJX1 and CJX2-treated group was 0.0508 and 0.0495 respectively, and higher than those of control group (0.0264) and verepamil-treated group (0.044) (Figure 2).

Effect of CJX1 and CJX2 on Rh123 efflux CJX1 and CJX2 1-10 $\mu \mathrm{mol} / \mathrm{L}$ inhibited the efflux of Rh123 from RBMEC from 0 to 100 min (Figure 3 ). The inhibitory effects remained even at $120 \mathrm{~min}$ after removal of CJX1 or CJX2 $2.5 \mu \mathrm{mol} / \mathrm{L}$ from the medium (Figure 4). This amount suggested that the inhibitory effects of CJX1 and CJX2 on P-gp function was reversible and that the inhibitory effects of CJX1 on P-gp persisted longer compared with verapamil. The efflux constants in CJX1 and CJX2 $10 \mu \mathrm{mol} / \mathrm{L}$-treated groups was 0.0097 and 0.0127 , respectively, and was lower than those in control group (0.0312) and verapamil-treated group (0.0131).
Table 1. Effect of CJX1 and CJX2 on the accumulation of Rh123 in rat brain microvessel endothelial cells (RBMEC) and human umbilical vein endothelial cells (HUVEC). $n=3$ experiments (each 4 wells). Mean \pm SD. ${ }^{\mathrm{c}} P<0.01$ vs control group. ${ }^{\mathrm{e}} P<0.05$ vs verapamil group.

\begin{tabular}{|c|c|c|c|c|}
\hline \multirow{2}{*}{\multicolumn{2}{|c|}{ Group $/ \mu \mathrm{mol} \cdot \mathrm{L}^{-1}$}} & \multirow{2}{*}{\multicolumn{3}{|c|}{$\mathrm{Rh} 123 / \mathrm{nmol} \cdot \mathrm{g}^{-1}$ protein }} \\
\hline & & & & \\
\hline Control & & $\begin{array}{l}\text { RBMEC } \\
68 \pm 10\end{array}$ & $\begin{array}{l}\text { HUVEC } \\
315 \pm 39\end{array}$ & $\begin{array}{c}\text { Increasing } \\
\text { rate } / \%\end{array}$ \\
\hline CJX1 & 1 & $91 \pm 6^{c}$ & & 34.1 \\
\hline & 2.5 & $197 \pm 30^{c}$ & & 191.4 \\
\hline \multirow{6}{*}{ CJX2 } & 5 & $282 \pm 44^{c}$ & & 316.5 \\
\hline & 10 & $323 \pm 11^{\mathrm{ce}}$ & $310 \pm 28$ & 377.1 \\
\hline & 1 & $85 \pm 12^{c}$ & & 25.9 \\
\hline & 2.5 & $161 \pm 31^{c}$ & & 137.8 \\
\hline & 5 & $220 \pm 28^{c}$ & & 224.9 \\
\hline & 10 & $282 \pm 44^{c}$ & $320 \pm 19$ & 317.2 \\
\hline Ver & 10 & $269 \pm 50^{c}$ & $320 \pm 53$ & 297.3 \\
\hline
\end{tabular}

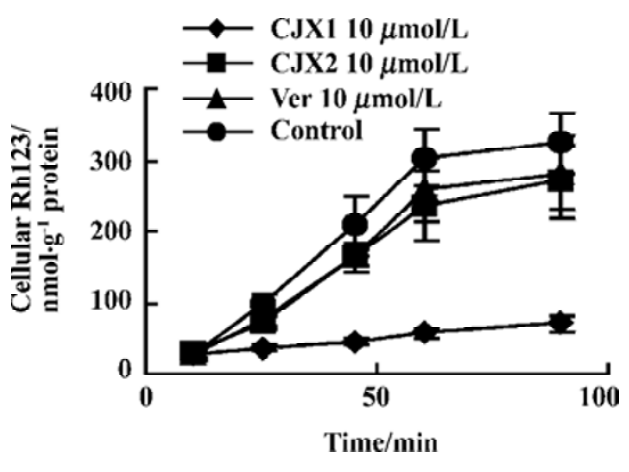

Figure 2. Effect of $\mathrm{CJX} 1$ and $\mathrm{CJX} 2$ on the uptake of Rh123 in rat brain microvessel endothelial cells. $n=3$ experiments (each 4 wells). Mean \pm SD.

\section{Discussion}

Beaulieu et al showed that P-gp was localized in the luminal membranes of RBMEC ${ }^{[15]}$. RBMEC was a valuable tool for the study of BBB permeability in vitro ${ }^{[13]}$; however, HUVEC was often used as a negative control and had no detectable P-gp expressions ${ }^{[16,17]}$. The efflux of fluorescent dye Rh123 was known to be P-gp-dependent and consequently was used extensively to determine the efflux rate from the cells expressing P-gp and to screen novel effective P-gp reversal agents ${ }^{[18]}$.

The present study showed that before the RBMEC and HUVEC were exposed to Rh123, the amount of intracellular Rh123 in RBMEC was lower than that in HUVEC. After CJX1 and CJX2 treatment, intracellular accumulation of $\mathrm{Rh} 123$ was elevated greatly in RBMEC in a concentration- 


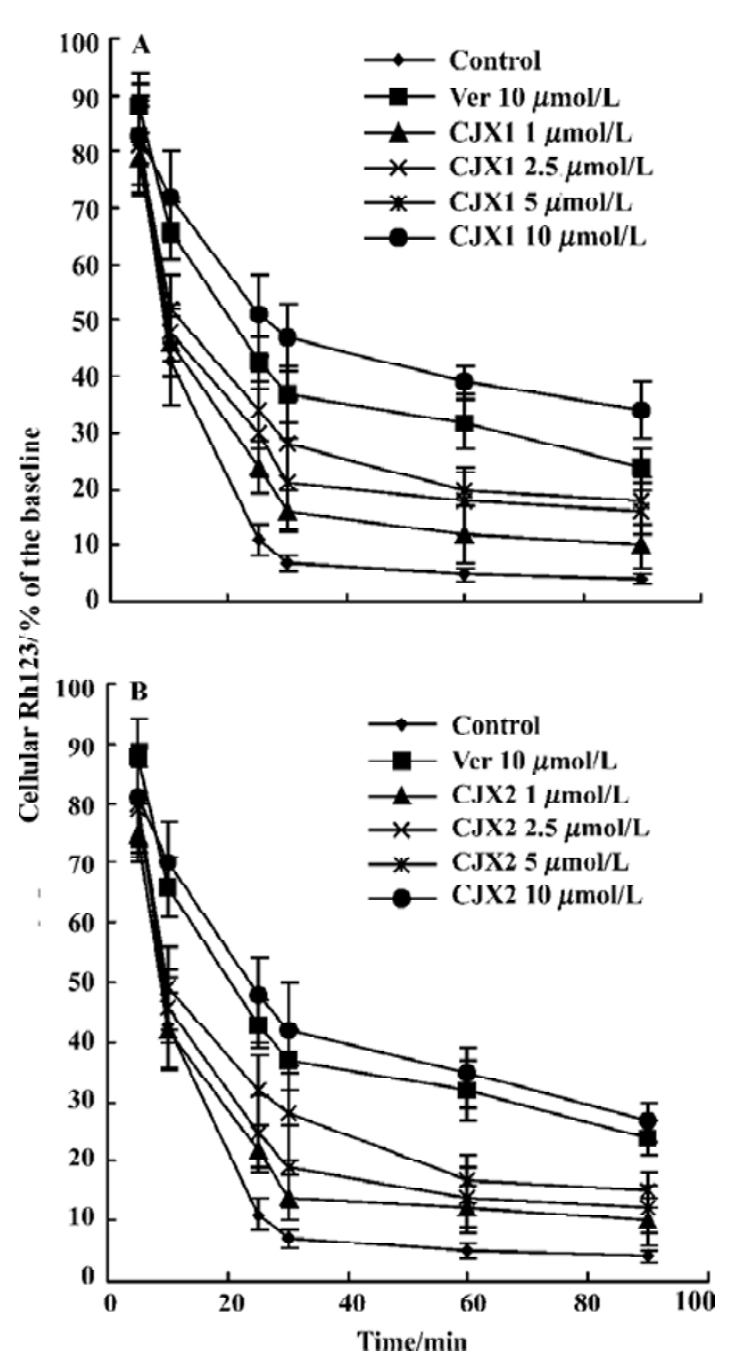

Figure 3. Effect of CJX1 (A) and CJX2 (B) on the efflux of Rh123 in rat brain microvessel endothelial cells. $n=3$ experiments (each 4 wells). Mean \pm SD.

dependent manner. But no increase was observed in HUVEC. The intracellular amounts of Rh123 in the CJX1 $10 \mu \mathrm{mol} / \mathrm{L}$ treated group were higher than those in the verapamil 10 $\mu \mathrm{mol} / \mathrm{L}-$ treated group. CJX1 and CJX2 significantly enhanced the uptake of Rh123 over the uptake phase. The uptake of Rh 123 by RBMEC was more rapid in the CJX1- and CJX2-treated group compared with verapamil-treated group. In contrast, CJX1 and CJX2 significantly reduced the efflux of Rh123. The efflux of Rh123 were slower in the CJX1and CJX2-treated groups than in the verapamil-treated group. All the results indicated that CJX1 had more potent effect in inhibiting the P-gp-mediated transport of Rh123.

The amount of Rh123 was decreased and returned to the control level after washout of CJX1 and CJX2 at different



Figure 4. Persistence of activity of CJX1 and CJX2. $n=3$ experiments (each 4 wells). Mean \pm SD.

time points. This suggested that $\mathrm{P}$-gp function recovered and the inhibitory effect of CJX1 and CJX2 on P-gp was reversible. The amount of Rh123 was less than $40 \%$ of basement at 60 min after washout of verapamil and CJX2. But in the CJX1-treated group, there was about 40\% Rh123 in RBMEC at 90 min after washout of CJX1. This result showed that the inhibitory effect of CJX1 persisted longer than that of verapamil.

The inhibitory effect of CJX1 and CJX2 on P-gp function in RBMEC indicated that the two compounds may be able to reverse MDR mediated by P-gp. This study has been performed on doxorubicin-resistant human myelogenous leukemia (K562/DOX) cells in our laboratory and the results will be published. The effect of CJX1 and CJX2 on P-gp function in vivo will be observed in our laboratory in the near future.

In conclusion, CJX1 and CJX2 exhibited a potent effect on the inhibition of P-gp function in vitro. They may become candidates of the effective P-gp reversal agents.

\section{References}

1 Germann UA. P-glycoprotein-a mediator of multidrug resistance in tumour cells. Eur J Cancer 1996; 32A: 927-44.

2 Gottesman MM, Pastan I. Biochemistry of multidrug resistance mediated by the multidrug transporter. Annu Rev Biochem 1993; 62: 385-427.

3 Childs S, Ling V. The MDR superfamily of genes and its biological implications. Important Adv Oncol 1994; 21-36.

4 Elsinga PH, Hendrikse NH, Bart J, Vaalburg W, van Waarde A. PET studies on P-glycoprotein function in the blood-brain barrier: how it affects uptake and binding of drugs within the CNS. Curr Pharm Des 2004; 10: 1493-503.

5 Cisternino S, Rousselle C, Debray M, Scherrmann JM. In vivo saturation of the transport of vinblastine and colchicine by P-glycoprotein at the rat blood-brain barrier. Pharm Res 2003; 20: 1607-11.

6 Zhao YL, Du J, Kanazawa H, Sugawara A, Takagi K, Kitaichi K, et al. Effect of endotoxin on doxorubicin transport across blood-brain 
barrier and P-glycoprotein function in mice. Eur J Pharmacol 2002; 445: 115-23.

7 Sakata A, Tamai I, Kawazu K, Deguchi Y, Ohnishi T, Saheki A, et al. In vivo evidence for ATP-dependent and P-glycoprotein-mediated transport of cyclosporin A at the blood-brain barrier. Biochem Pharmacol 1994; 48: 1989-92.

8 Twentyman PR. Modification of cytotoxic drug resistance by nonimmuno-suppressive cyclosporins. Br J Cancer 1988; 57: 254-8.

9 Aszalos A, Thompson K, Yin JJ, Ross DD. Combinations of P-glycoprotein blockers, verapamil, PSC 833, and cremophor act differently on the multidrug resistance associated protein (MRP) and on P-glycoprotein (Pgp). Anticancer Res 1999; 19: 1053-64.

10 Ohbayashi Y, Tsutamoto T, Sakaguchi T, Tanaka T, Kanamori T, Yokohama $\mathrm{H}$, et al. Effect of an angiotensin II type 1 receptor blocker, valsartan, on neurohumoral factors in patients with hypertension: comparison with a long-acting calcium channel antagonist, amlodipine. J Cardiovasc Pharmacol 2003; 42 Suppl 1: S71-4.

11 Katoh M, Nakajima, M, Yamazaki H, Yokoi T. Inhibitory potencies of 1,4-dihydropyridine calcium antagonists to P-glycoprotein-mediated transport: comparison with the effects on CYP3A4. Pharm Res 2000; 17: 1189-97.

12 Abbott NJ, Hughes CC, Revest PA, Greenwood J. Development and characterization of a rat brain capillary endothelial culture: towards an in vitro blood-brain barrier. J Cell Sci 1992; 103: 23-37.

13 Fontaine M, Elmquist WF, Miller DW. Use of rhodamine 123 to examine the functional activity of $\mathrm{P}$-glycoprotein in primary cultured brain microvessel endothelial cell monolayers. Life Sci 1996; 59: 1521-31.

14 Sarver JG, Klis WA, Byers JP, Erhardt PW. Microplate screening of the differential effects of test agents on Hoechst 33342, rhodamine 123 , and rhodamine $6 \mathrm{G}$ accumulation in breast cancer cells that overexpress P-glycoprotein. J Biomol Screen 2002; 7: 29-34.

15 Beaulieu E, Demeule M, Ghitescu L, Beliveau R. P-glycoprotein is strongly expressed in the luminal membranes of the endothelium of blood vessels in the brain. Biochem J 1997; 326 ( Pt 2): 539-44.

16 Zhu HJ, Liu GQ. Effect of E6, a novel calmodulin inhibitor, on activity of P-glycoprotein in purified primary cultured rat brain microvessel endothelial cells. Acta Pharmacol Sin 2003; 24: 1143-9.

17 He L, Liu GQ. Effects of various principles from Chinese herbal medicine on rhodamine 123 accumulation in brain capillary endothelial cells. Acta Pharmacol Sin 2002; 23: 591-6.

18 Green LJ, Marder P, Slapak CA. Modulation by LY335979 of P-glycoprotein function in multidrug-resistant cell lines and human natural killer cells. Biochem Pharmacol 2001; 61: 1393-9. 